\title{
The Role of Granulocytes in the Pulmonary Response to Group B Streptococcal Toxin in Young Lambs
}

\author{
BARBARA ENGELHARDT, KENNETH SANDBERG, DONNA BRATTON, \\ ANNICK VAN DEN ABBEELE, JENS GROGAARD, CARL HELLERQVIST, AND \\ HÅKAN SUNDELL \\ Department of Pediatrics and Biochemistry, Vanderbilt University School of Medicine, \\ Nashville, Tennessee 37232
}

\begin{abstract}
Marked leukopenia and sequestration of granulocytes in the lung are consistently seen in severe early onset group B streptococcal (GBS) disease in human infants. To investigate the role of granulocytes as potential mediators in the pulmonary pathophysiology of this disease, the effects of intravenously administered GBS type III toxin were studied in young lambs before and after granulocyte depletion with hydroxyurea. Granulocyte depletion markedly reduced the 4-fold increase in total lung resistance and the decrease in dynamic compliance observed after GBS toxin. Granulocyte depletion significantly attenuated the pulmonary hypertension, hypoxemia and increased minute ventilation present during the first phase of the response (0.5-1 h after GBS toxin). It did not significantly alter the increase in body temperature, the marked increase in lung lymph thromboxane $B_{2}$ concentrations during the first phase or the increase in lung lymph flow and protein clearance during the second phase of the response (3.5-5 $\mathrm{h}$ after GBS toxin). The results indicate that granulocytes are involved as mediators of the changes in lung mechanics seen after GBS toxin infusion in young lambs. Granulocytes contribute to the pulmonary hypertension and decrease in arterial oxygenation, but other mediators appear to be responsible for the injury of the vascular endothelium. (Pediatr Res 21: 159-165, 1987)
\end{abstract}

\section{Abbreviations}

$\mathrm{C}_{\mathrm{dyn}}$, dynamic compliance

GBS, group B streptococcus

$\mathrm{L} / \mathrm{P}$, lymph/plasma protein ratio

$\mathbf{P}_{\mathrm{pa}}$, pulmonary artery pressure

TXB $_{2}$, thromboxane $B_{2}$

TGV, thoracic gas volume

$V_{T}$, tidal volume

$\dot{\mathrm{V}}_{\text {min }}$, minute ventilation

$\mathbf{P}_{\mathrm{pl}}$, pleural pressure

$\dot{\mathrm{V}}$, flow

$\mathbf{P}_{\text {ao, }}$, airway opening pressure

$P_{\text {tp }}$, transpulmonary pressure

$\mathrm{SG}_{\mathbf{l}}$, specific conductance

$\mathrm{f}$, frequency
$\mathbf{R}_{\mathrm{L}}$, resistance to air flow across the lungs

Infection with GBS in the early neonatal period is associated with a high mortality in spite of appropriate antibiotic therapy (1). Severe disease presents with respiratory failure, leukopenia, and cardiovascular collapse. Isolation of a toxin from type III GBS cultures obtained from an infant who died with GBS pneumonia, has provided a tool for studies of the pathophysiology involved in this disease (2-6). Infusion of this toxin into sheep causes a 2-phase reaction with initial pulmonary hypertension associated with tachypnea, chills, and fever, followed by a second phase characterized by increased flow of lung lymph, rich in protein, indicating an increased vascular permeability. A similar reaction as well as alterations of lung mechanics has been described after Escherichia coli endotoxin infusion in sheep (79). As in GBS pneumonia in newborn infants, granulocytopenia with pulmonary sequestration of granulocytes occurs during the GBS toxin reaction in sheep (4).

Pulmonary vasoconstriction during the first phase of the GBS toxin reaction is assumed to be mediated by arachidonic acid metabolites, such as thromboxane $A_{2}$, which cannot be measured in body fluids due to its short half life. Plasma levels of its stable metabolite, $\mathrm{TXB}_{2}$, increase during intravenous infusion with live GBS bacteria in piglets (10), and a marked increase in $\mathrm{TXB}_{2}$ lung lymph concentrations is seen during the first phase of the GBS toxin reaction in sheep (5). The first phase pulmonary hypertensive response to GBS toxin infusion in sheep can be blocked by cyclooxygenase inhibition (5). The vascular permeability changes are, however, not blocked by cyclooxygenase inhibition.

The degree of granulocytopenia during the GBS toxin response correlates positively with the increase in vascular permeability, as indicated by an increased lung lumph protein clearance (4). Leukopenia and increased lymph protein clearance following GBS toxin can be blocked by pretreatment with methylprednisolone (6). Granulocytes have, therefore, been implicated as mediators of the vascular damage (4). There are in vivo and in vitro studies showing that granulocytes can release thromboxane after $E$. coli endotoxin challenge (11), so they might also play a role in mediating toxin-induced pulmonary vasoconstriction.

The purpose of this study was to test the hypothesis that the increased vascular permeability to protein, pulmonary hypertension, and alterations in lung mechanics seen after GBS toxin administration in sheep are mediated by granulocytes sequestered in the lung. Young lambs were studied before and after granulocyte depletion. Hydroxyurea was used to induce granulocyte depletion because it acts predominantly on the granulocytes, and it is well tolerated by the animals.

\section{MATERIALS AND METHODS}

Correspondence and reprint requests Håkan Sundell, M.D., Associate Professor of Pediatrics, Vanderbilt University, School of Medicine, Nashville. TN 37232.

Supported by Grant HL 14214 from the National Institute of Health and Grant HL07256 from National Heart. Lung and Blood Institute
Preparation. Twelve lambs were instrumented 1 to 10 days after birth with placement of catheters in a femoral artery and a 
tarsal vein. A 5 Fr. Swan Ganz catheter was introduced through a jugular vein sheath on the day of the study. A right thoracotomy was done to obtain a chronic lung lymph fistula. The efferent duct of the caudal mediastinal node was cannulated with a silastic catheter. To avoid contamination from abdominal and systemic lymphatics, the caudal portion of the lymph node and diaphragmatic lymph vessels were ligated. In the animals whose lung functions were studied, two pleural balloons (silastic envelopes) were placed in the right pleural space. A tracheostomy was performed the day prior to the first study. In the postoperative period, all lambs received $50,000 \mathrm{U} / \mathrm{kg} /$ day of procain penicillin and $40 \mathrm{mg} / \mathrm{kg} /$ day of dihydrostreptomycin intramuscularly for 3 days. The lambs were allowed to recover an average of 8 days (range 2-14 days) after surgery before they were studied the first time. Lambs with lymph preparations were chronically heparinized to decrease the risk of clots in the lymph fistula. All lambs received $2000 \mathrm{U}$ heparin intravenously on the morning of the studies. Five lambs were used for lymph studies, five lambs for studies of lung mechanics and two lambs for both.

Study protocol. All lambs. were studied at least two times. First, they were studied in a control state with normal white cell count and the second time they were studied after depletion with 100 $\mathrm{mg} / \mathrm{kg} /$ day of hydroxyurea (Hydrea, E. R. Squibb \& Sons Inc., Princeton, NJ), until the granulocyte count was below 200 cells/ $\mathrm{mm}^{3}$. The hydroxyurea was dissolved in $10 \mathrm{ml}$ normal saline, filtered through a millipore filter, and given intravenously. While in the granulocyte-depleted state, the lambs had an increased susceptibility to infections. Therefore, antibiotics in the form of penicillin $50,000 \mathrm{U} / \mathrm{kg} /$ day and dihydrostreptomycin $40 \mathrm{mg} / \mathrm{kg} /$ day or gentamycin $5 \mathrm{mg} / \mathrm{kg} /$ day were restarted before the control study and were given during granulocyte depletion until repletion had occurred. The lambs were only studied in the depleted state if they were afebrile and appeared healthy, were eating well, gaining weight, and were free of obvious infections. Outcome of the lambs following the study in the depleted study varied. Five lambs were studied after spontaneous recovery of the granulocyte count 6-12 days (mean 10 days) later. Four lambs were killed $0-48$ days (mean 21 days) later because of slow repletion of the granulocyte count, catheter failure, or scheduling problems. Three lambs were killed 4-7 days (mean 5 days) later because of illness.

The average age of the lambs during the first study was 15 days (range 4-22 days), 23 days (range 19-41 days) during the second study and 31 days (range 26-37 days) during the third study. Their mean weights were $7.6 \mathrm{~kg}$ (range $3.6-11.2 \mathrm{~kg}$ ) on the day of the first study, $8.7 \mathrm{~kg}$ (range $4.4-13 \mathrm{~kg}$ ) on the day of the second study, and $9.3 \mathrm{~kg}$ (range $7.3-14.5 \mathrm{~kg}$ ) on the day of the third study.

After stable baseline measurements during 1.5 to $2 \mathrm{~h}, 100 \mu \mathrm{g} /$ $\mathrm{kg}$ of GBS toxin mixed in $30 \mathrm{ml}$ of normal saline was infused intravenously during $12 \mathrm{~min}$. The response was monitored for at least $3 \mathrm{~h}$ in all lambs and for $5 \mathrm{~h}$ in most lambs.

Measurements. The lambs were studied unanesthetized standing in a loose sling. Respiratory rate and rectal temperature (YSI tele-thermometer, Yellow Springs Instrument Co., Yellow Springs, $\mathrm{OH}$ ) were recorded every $15 \mathrm{~min}$. Heart rate and vascular pressures (pressure transducers: Statham P23Gb Gould Statham Instruments, Inc., Hato Rey, Puerto Rico; electronic recorder: model 8800 S Hewlett-Packard Co., Palo Alto, CA) were measured continuously and recorded every $15 \mathrm{~min}$. The transducers were kept at the level of the heart of the lambs. Pulmonary capillary wedge pressures were measured through a Swan Ganz catheter, after that the balloon had been inflated with $0.8 \mathrm{ml} \mathrm{CO}$. Lung lymph was collected into a graduated tube coated with heparin, EDTA, and indomethacin. Lymph flow was recorded every $15 \mathrm{~min}$, and lymph was pooled every $30 \mathrm{~min}$ for analyses. Lymph protein concentration was determined on every collection. Lymph concentrations of $\mathrm{TXB}_{2}$ and 6-keto$\mathrm{PGF}_{1 \alpha x}$ (a prostacyclin metabolite) were determined during baseline, and every hour for $5 \mathrm{~h}$ after toxin infusion. Plasma total protein concentration was determined every hour. Two white cell counts were done during baseline and at 60,90, 120, 180, 240 , and $300 \mathrm{~min}$ after toxin infusion. Arterial blood gases and $\mathrm{pH}$ were analyzed during baseline, at the peak of pulmonary hypertension in phase I, and every $60 \mathrm{~min}$ throughout the experiment. A respiratory quotient of 0.8 was assumed when alveolar arterial differences were calculated. Lymph protein clearance was calculated by multiplying lymph/plasma protein ratio by lymph flow.

Lung mechanics. During the lung mechanics measurements, the lamb was standing in a whole body pressure-compensated integrated-flow plethysmograph. The volume of the box was 165 liters. The cuffed, rigid tracheostomy tube was connected via a flexible non-collapsible tubing extending through the wall to a valve. The valve could automatically occlude the airway for TGV determinations. The solenoid-activated shutter in this valve occluded the airway within the first few milliseconds of inspiration and held it closed a preset time of 1 to $5 \mathrm{~s}$. The shutter was triggered by zero crossing of the plethysmograph pressure from negative to positive. There was a constant bias air flow through the valve to reduce the dead space of the tubing. $V_{\mathrm{T}}$ was measured by pressure compensating the integrated pressure signal from the plethysmograph. $\dot{V}_{\min }$ was calculated as an average $V_{\mathrm{T}}$ times respiratory $\mathrm{f}$ or by integrating $\mathrm{V}_{\mathrm{T}}$ over $1 \mathrm{~min}$ with a HewlettPackard respiratory integrator. $\dot{V}$ was obtained by electrically differentiating the volume signal. $\mathrm{P}_{\mathrm{pl}}$ was measured in a pleural balloon placed in the pleural space. $P_{a o}$ was measured through a catheter with multiple side holes located 0.5 to $1 \mathrm{~cm}$ past the distal end of the tracheostomy tube. $P_{t p}$ was measured as the difference between $P_{p l}$ and $P_{a o}$. Validyne differential transducers (model MP-45, Validyne Engineering Corp., Northridge, CA) and Hewlett Packard amplifiers (Hewlett-Packard Medical Products, Andover, MA) were used. The signals from the transducers with connecting catheters and pleural balloons were tuned to eliminate phasic distortion up to $8 \mathrm{~Hz}$.

Before each measurement of lung mechanics, the lungs of the lamb were inflated to $20 \mathrm{~cm} \mathrm{H}_{2} \mathrm{O}$ of $\mathrm{P}_{\text {ao }}$. Simultaneous $\mathrm{V} / \dot{\mathrm{V}}$ and $\mathrm{V} / \mathrm{P}_{\mathrm{tp}}$ curves were displayed on a Tektronix dual-beam storage oscilloscope and photographed for further calculations of lung mechanics. $\mathrm{C}_{\mathrm{dyn}}$ was calculated as $\mathrm{V}_{\mathrm{T}} / \mathrm{P}_{\mathrm{tp}}$ at points of zero flow. Total $R_{L}$ was calculated as $P_{t p} / \dot{V}$ at midtidal volume by using the method of von Neergaard and Wirz (12). Specific dynamic lung compliance was calculated as $C_{d y n} / T G V$ and $S_{L}$ as $1 / R_{L} /$ TGV. TGV was measured according to DuBois et al. (13) using the $P_{a o}$ and plethysmographic volume changes obtained during airway occlusion at end expiration. Measurements were performed every 5 to $15 \mathrm{~min}$.

Laboratory analysis. White blood cells were counted using a model 2BI Coulter counter (Coulter Electronics, Hialeah, FL), specifically adjusted for counting sheep. A blood smear was stained with Wright's stain to determine the number of granulocytes and lymphocytes/100 white cells. The same procedures were used for determination of lymph white cells. Protein content of blood and lymph was analyzed by a modified biuret method on an automated analysis system (Auto Analyzer Technicon Instruments Corp., Tarrytown, NY). $\mathrm{TXB}_{2}$ and 6-keto-prostaglandin $\mathrm{F}_{1 \alpha}$ concentrations in lung lymph were measured with a radioimmunoassay as previously described in detail (6). Arterial blood gas determinations were made with a blood gas analyzer (Corning model 158, Corning Medical and Scientific, Medfield, MA).

Statistics. Each lamb was studied in control and depleted states. The results are presented as mean \pm SEM. To test statistical significance of differences over time in each of the two states, control and granulocyte depleted, and to test the significance of differences between states we used two-way analysis of variance. The null hypothesis was rejected for $p<0.05$. Duncan's multiple range test was then used for significance of differences within states at the $p<0.05$ level. Lambs who did not have complete data for all time periods in both states, e.g. due to catheter failure or sample loss, were not used for statistical analysis of differences. 


\section{RESULTS}

Effect of granulocyte depletion on baseline variables. Hydroxyurea markedly reduced total white blood cell counts (Fig. 1). After hydroxyurea, the granulocyte count had a range of $0-175$ cells $/ \mathrm{mm}^{3}$. The blood lymphocyte count was also reduced but not to the same extent as the granulocyte count. The cell count in lymph, which predominantly consisted of lymphocytes, was significantly reduced from $23171 \pm 9454$ to $4951 \pm 541$ cells/ $\mathrm{mm}^{3}$ after hydroxyurea. $\mathrm{C}_{\text {dyn }}$ was significantly higher after hydroxyurea treatment $\left(11.7 \pm 1.7\right.$ versus $\left.15.1 \pm 2.3 \mathrm{ml} / \mathrm{cm} \mathrm{H}_{2} \mathrm{O}\right)$. Other baseline variables were not significantly altered by hydroxyurea.

Response to GBS toxin. Results of leucocyte, hemodynamic, and lymph measurements are presented as group means \pm SEM of single measurements every 15-60 min for $5 \mathrm{~h}$ after GBS toxin in Figures 1 and 2. Group means \pm SEM of peak values during phase I ( $0.5-1 \mathrm{~h}$ after GBS toxin) and averaged values during phase II, the stable period, 3.5-5 $\mathrm{h}$ after GBS toxin were also calculated, as was done in our previous reports of the GBS toxin response (2-6).

White Cells. Total white blood cell and granulocyte counts decreased abruptly at $1 \mathrm{~h}$ after GBS toxin in the control studies and increased progressively thereafter as shown in Figure 1. The lymphocyte count also decreased at $1 \mathrm{~h}$ but remained decreased. Figure 1 (bottom) illustrates the corresponding cell counts during the depleted studies. The lymphocyte count also decreased significantly in lung lymph during the control studies from 23171 \pm 9454 to $7909 \pm 3994$ cells $/ \mathrm{mm}^{3}$ during phase II. The corre-
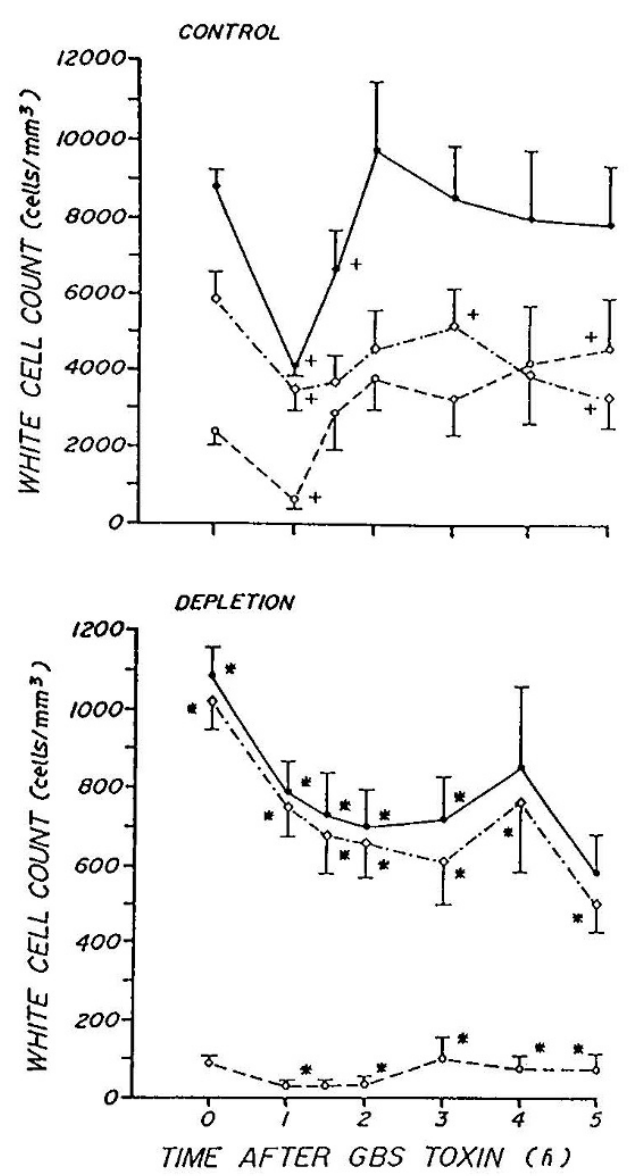

Fig. 1. Effect of GBS toxin on total white blood cell granulocyte $\left(\mathrm{O}_{-}-\mathrm{O}\right)$ and lymphocyte $\left(\diamond_{--}-\diamond_{)}\right.$counts in young lambs studied before (control) and after granulocyte depletion. Values are mean $\pm \mathrm{SE} ; n=11$ until $3 \mathrm{~h}$ and $7-8$ thereafter. $\dagger$ Significantly different compared to baseline. ${ }^{*}$ Significantly different compared to control state: $p<0.05$.
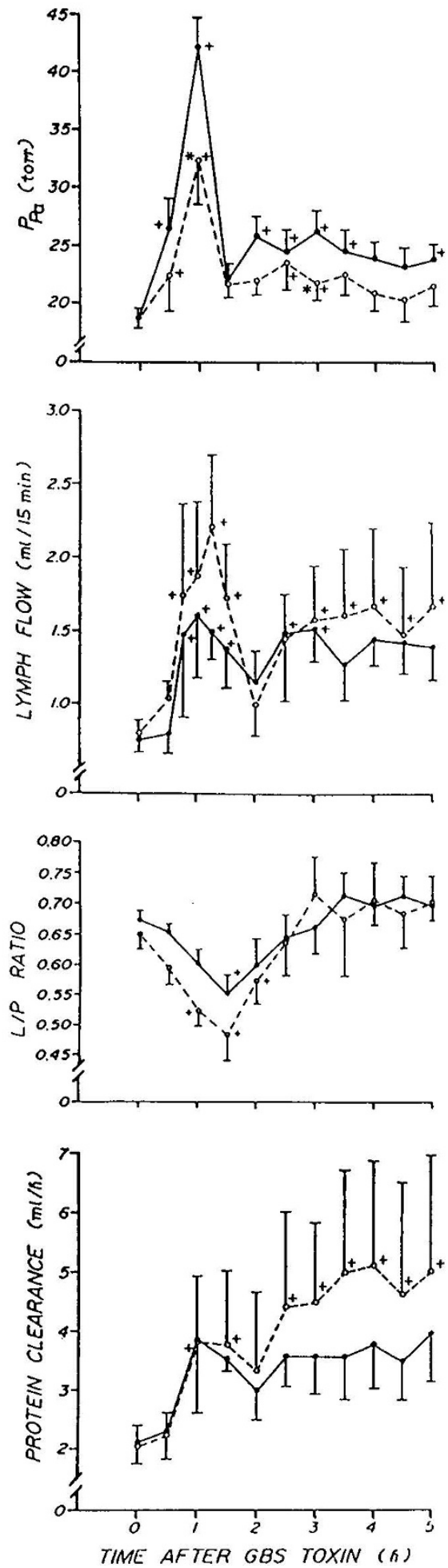

Fig. 2. $\mathrm{P}_{\mathrm{pa}}$, lung lymph flow, $\mathrm{L} / \mathrm{P}$ ratio, and lung lymph protein clearance changes after GBS toxin in young lambs studied before $(-)$ and after granulocyte depletion $(\mathrm{O}--\mathrm{O})$. Values are mean \pm SE; $n=11$ until $3 \mathrm{~h}$ and 7-9 thereafter for $\mathrm{P}_{\mathrm{pa}}, n=7$ for lymph flow and $n=6$ for $\mathrm{L} / \mathrm{P}$ ratio and protein clearance. $\dagger$ Significantly different compared to baseline, ${ }^{*}$ significantly different compared to control state, $p<0.05$.

sponding change from $4951 \pm 541$ to $1765 \pm 794$ cells $/ \mathrm{mm}^{3}$ during the depletion studies was not statistically significant.

Blood Pressure and Heart Rate. Systemic blood pressure increased significantly in phase $I$ in both states $(81 \pm 3$ to $88 \pm 4$ and $83 \pm 3$ to $90 \pm 3$ torr, respectively). No significant changes 
were observed in heart rate during the GBS toxin reaction. A biphasic increase in pulmonary arterial pressure was noted after GBS toxin (Fig. 2). The first peak of the pressure response occurred at $45-60$ min after GBS toxin infusion. The second phase of the $P_{p a}$ increase was highest 2-3 h after toxin infusion, and it lasted longer. $P_{\mathrm{pa}}$ did not reach baseline values at the end of the control study. After granulocyte depletion, $\mathrm{P}_{\mathrm{pa}}$ after GBS toxin infusion followed the same pattern but was significantly lower than in the control state at 1 and $3 \mathrm{~h}$. Pulmonary wedge pressures increased significantly during phase $I$ in both the control and depleted state $(3.3 \pm 0.8$ to $8.6 \pm 1.4$ and $5.3 \pm 1.1$ to $8.4 \pm 1.9$ torr, respectively).

Lung Fluid Balance. A biphasic increase in lung lymph flow occurred in the control state, which was not significantly different in the depleted state (Fig. 2). L/P ratios decreased in phase I and increased thereafter (Fig. 2). There was not a significant or consistent effect of granulocyte depletion on lung lymph protein clearance (Fig. 2). Compared to the control state, the increase in protein clearance during phase II of the GBS toxin response was greater in the depleted state in three lambs, smaller in two, and unchanged in one lamb.

Prostaglandins. Lung lymph $\mathrm{TXB}_{2}$ concentrations increased significantly in phase I in both control and depleted states. Control and depletion measurements were not significantly different. Figure 3 illustrates that the increase in $\mathrm{TXB}_{2}$ lung lymph concentrations was discrete at $1 \mathrm{~h}$ after GBS toxin. No significant changes were seen in 6-keto-prostaglandin $\mathrm{F}_{1 \alpha}$ lymph concentrations after GBS toxin.

Temperature. Body temperature increased significantly and peaked at $1 \mathrm{~h}$ and $15 \mathrm{~min}$ after GBS toxin in both control and depleted states $(39.7 \pm 0.1$ to $40.9 \pm 0.1$ and $39.8 \pm 0.1$ to 40.7 $\pm 0.3^{\circ} \mathrm{C}$, respectively).

Lung Mechanics. A biphasic response was observed with peak values at $0.5-1$ and $2-3 \mathrm{~h}$. Results of lung mechanics measurements are presented as percent of baseline in Figure 4. In the control study, total lung resistance was increased at $0.5-1$ and 2-3 $\mathrm{h}$ after GBS toxin infusion. After granulocyte depletion, no significant changes in $\mathrm{R}_{\mathrm{L}}$ compared to baseline values were observed after toxin. Compared to the control study, the reaction in the depleted state was significantly attenuated. The same differences were observed in specific conductance. Compared to baseline, there was a decrease in $C_{\mathrm{dyn}} 0.5-1$ and 2-3 $\mathrm{h}$ after toxin infusion in the control study. These changes were not found in the granulocyte-depleted state, which had significantly higher $\mathrm{C}_{\mathrm{dyn}}$ at these times compared to the control study. The same differences were observed in specific dynamic compliance. The

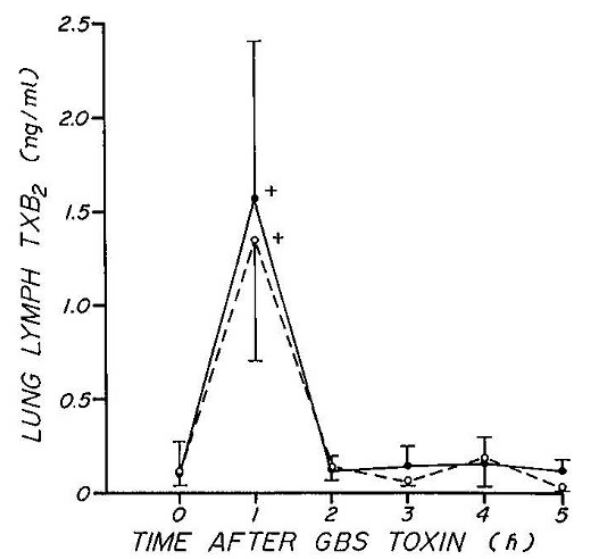

Fig. 3. Effect of GBS toxin on lung lymph concentrations of $\mathrm{TXB}_{2}$ in young lambs studied before (- ) and after granulocyte depletion $(\mathrm{O}--\mathrm{O})$. Values are mean \pm SE: $n=5$ until $1 \mathrm{~h}$ and $2-5$ thereafter. $\uparrow$ Significantly different compared to baseline: $p<0.05$. changes in TGV were less obvious although there was a trend toward a biphasic decrease in TGV coinciding with the changes in lung mechanics.

Ventilation and Gas Exchange. Compared to baseline, there was a slight but insignificant increase in tidal volume and a significant increase in respiratory rate at $0.5-1 \mathrm{~h}$ after toxin infusion in the control study $(47 \pm 4$ to $55 \pm 6$ breaths per $\mathrm{min})$. The significant increase in $\dot{V}$ min during phase $I$ in the control state $(2507 \pm 309$ to $3473 \pm 484 \mathrm{ml} / \mathrm{min})$ was significantly reduced $(2366 \pm 204$ to $2788 \pm 389 \mathrm{ml} / \mathrm{min})$ after depletion. Arterial $\mathrm{PO}_{2}$ was lower compared to baseline measurements at $0.5-1$ and $2-3 \mathrm{~h}$ after toxin in the control study $(89 \pm 3,68 \pm 3$, and $81 \pm 3$ torr, respectively). This decrease in $\mathrm{PO}_{2}$ was attenuated to $77 \pm 3$ torr at $0.5-1 \mathrm{~h}$ after toxin in the depleted state. Arterial $\mathrm{PCO}_{2}$ and $\mathrm{pH}$ did not change significantly in either state. Alveolar-arterial $\mathrm{PO}_{2}$ differences $(\triangle \mathrm{AaPO})$ were increased at 1 and 2-5 h after GBS toxin as illustrated in Figure 5. At $1 \mathrm{~h}$ after GBS toxin, $\triangle \mathrm{AaPO}_{2}$ was significantly lower in the depleted compared to the control state.

Repletion. Five lambs were studied three times, before granulocyte depletion, after depletion, and finally after spontaneous granulocyte repletion. Due to the long interval between the studies several catheters were no longer functioning, and complete studies could not be performed. All lambs, however, had measurements of $\mathrm{P}_{\mathrm{pa}}$ and white blood cell counts. There was not a significant difference between the GBS toxin-induced maximum increase in $\mathrm{P}_{\mathrm{pa}}$ during the first control studies and the studies in the repleted state $(127 \pm 31$ and $112 \pm 39 \%$, respectively). The decrease in granulocyte count after GBS toxin was not significantly different when the first control studies was compared to the studies in the repleted state $(55 \pm 20$ and $66 \pm$ $13 \%$, respectively).

\section{DISCUSSION}

In this study, we found that granulocyte depletion with hydroxyurea markedly attenuated the GBS toxin-induced changes in lung mechanics in young lambs. Reductions of the pulmonary hypertension and decrease in oxygenation were also seen. We found, however, no significant effect on lymph protein clearance, an index of vascular permeability to protein or lung lymph prostaglandin metabolites.

In the control state, before hydroxyurea-induced granulocyte depletion, a similar response to GBS toxin was seen in the 1- to 2-wk-old lamb as has earlier been described in the adult sheep (3). The GBS toxin-induced biphasic changes in lung mechanics were characterized by a significant increase in $R_{L}$ and a decrease in $C_{\text {dyn. }}$ A slight decrease in TGV with a biphasic tendency paralleling the changes in lung mechanics was also noticed.

Inhibition of the arachidonic acid metabolism by indomethacin blocks the pulmonary hypertension after both $E$. coli endotoxin (14) and GBS toxin (5). Meclofenamate (8) attenuates the $E$. coli endotoxin-induced early changes in lung mechanics and pulmonary pressure. This has led to the assumption that prostaglandins, such as thromboxane $\mathrm{A}_{2}$, are mediators of toxininduced pulmonary hypertension, and that they also may be involved in the changes of lung mechanics during the first phase of the response.

Granulocyte depletion delayed and markedly attenuated the GBS toxin-induced biphasic increase in $R_{L}$ and decrease in $C_{d y n}$. The changes in specific conductance and specific dynamic compliance were also attenuated in the depleted state. The reduction of the GBS toxin-induced changes in lung mechanics, TGV, and oxygenation are similar to what have been found in leukopenic sheep after $E$. coli endotoxin infusion (7).

Pulmonary hypertension was significantly reduced in the first phase of the GBS toxin response in the depleted lambs, and the average $P_{p a}$ was consistently lower throughout the response. In contrast, granulocyte depletion with hydroxyurea did not signif- 

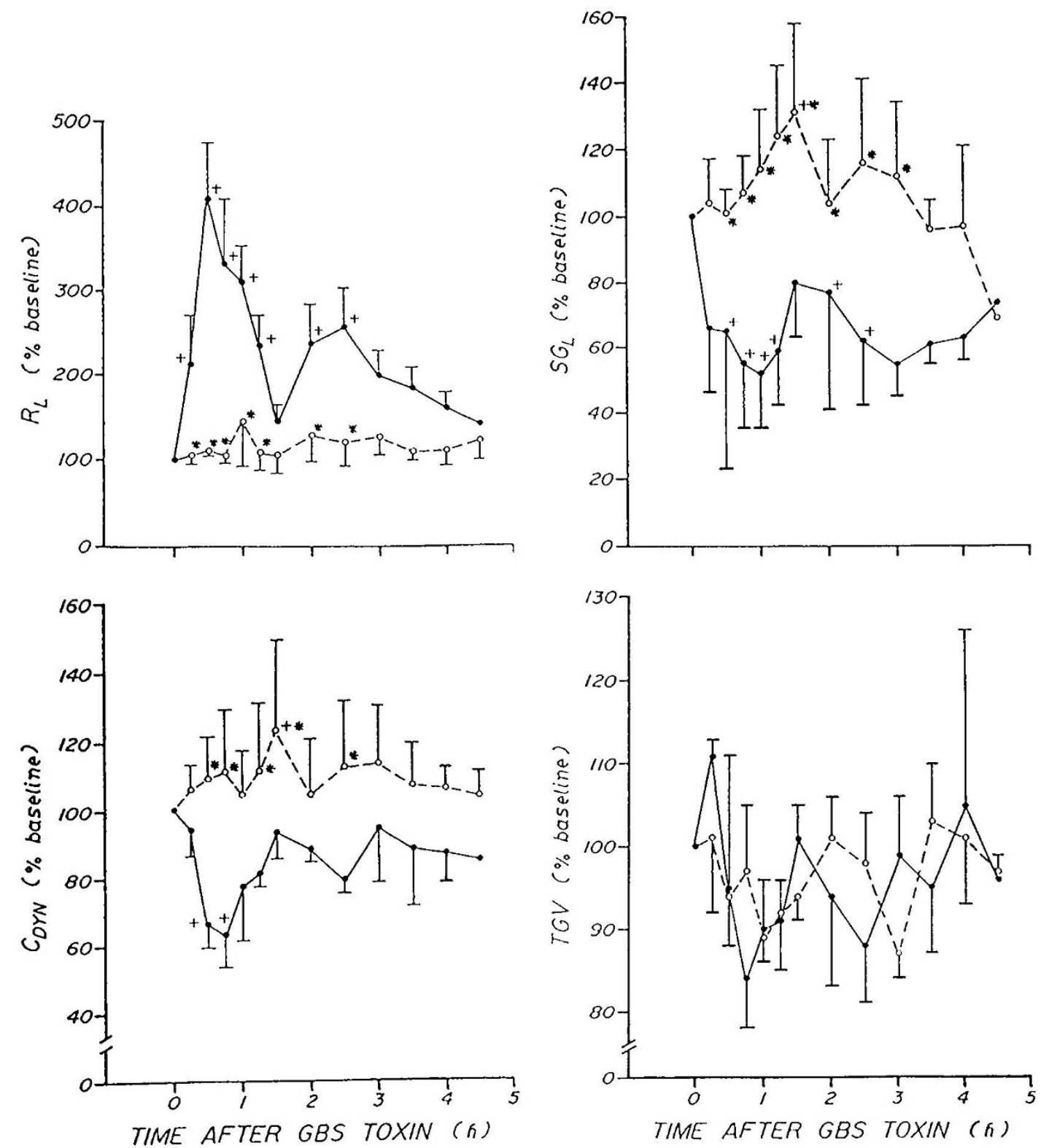

Fig. 4. $R_{L}, S_{L}, C_{d y n}$, and $T G V$ changes in young lambs before ( 7 until $3 \mathrm{~h}$ and $2-6$ thereafter. $\uparrow$ Significantly different compared to baseline $*$

and after granulocyte depletion $(\mathrm{O}--\mathrm{O})$. Values are mean $\pm \mathrm{SE} ; n=$ Significantly different compared to control state: $p<0.05$.

icantly affect the $E$. coli endotoxin-induced pulmonary hypertension $(7,9)$ although the endotoxin-induced pulmonary hypertension was attenuated after granulocyte depletion with nitrogen mustard (15). In vivo and in vitro experiments have shown that granulocytes are capable of synthesis of vasoactive substances after endotoxin stimulation $(8,11)$. Granulocyte depletion should, therefore, reduce the source for these vasoactive metabolites, thereby explaining the reduction in pulmonary hypertension found in our study. Participation of other cells in the lung, such as the endothelial cells in the synthesis of vasoactive arachidonic acid metabolites is, however, not excluded (16).

The marked increase in lung lymph levels of $\mathrm{TXB}_{2}$ was not attenuated by granulocyte depletion. These results and those of Hinson et al. (7), who studied the $E$. coli endotoxin reaction, therefore, indicate that granulocytes might not be the main source of $\mathrm{TXB}_{2}$ concentrations in lung lymph following toxin administration. Since the changes in lung mechanics were markedly attenuated by granulocyte depletion but not the marked increase in lung lymph levels of $\mathrm{TXB}_{2}$, it is not likely that thromboxane- $\mathrm{A}_{2}$ is the only mediator of the changes in lung mechanics. It is, however, possible that lung lymph levels of $\mathrm{TXB}_{2}$ do not reflect local thromboxane concentrations in the airways.

In this study, there was no consistent effect of granulocyte depletion on the GBS toxin-induced increase in lung lymph protein clearance. We expected to find a reduced protein clearance response to GBS toxin, since we previously have demonstrated a significant correlation between the decrease in circulating granulocyte counts and the increase in protein clearance and have found that granulocytes sequester in the lungs after GBS toxin (4). The pulmonary response to GBS toxin could theoretically be explained by release of active substances from activated granulocytes, e.g. arachidonate products (17), oxygen free radicals $(18,19)$, and proteolytic enzymes (20). Participation of granulocytes has been described in other forms of pulmonary injury, e.g. adult respiratory distress syndrome (21), and experimentally in sheep from $E$. coli endotoxin (7-9, 15), microembolization (22), and oxygen toxicity (23). Pulmonary sequestra- 


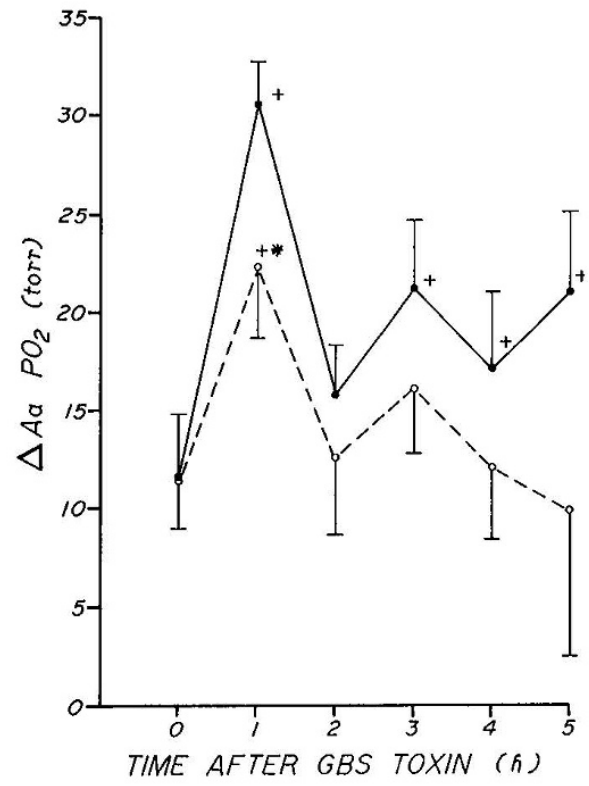

Fig. 5. Alveolar-arterial $\mathrm{PO}_{2}$ differences $\left(\triangle \mathrm{AaPO}_{2}\right)$ in young lambs given GBS toxin before (-— $(-)$ and after granulocyte depletion $(\mathrm{O}--\mathrm{O})$. Values are mean $\pm \mathrm{SE} ; n=12$ until $3 \mathrm{~h}$ and 5-9 thereafter. $\uparrow$ Significantly different compared to baseline. ${ }^{*}$ Significantly different compared to control state: $p<0.05$.

tion of granulocytes does, however, not in itself necessarily induce severe vascular injury as illustrated in some clinical situations, e.g. in patients undergoing hemodialysis (24), cardiopulmonary bypass (25), or experimentally in animals after infusion of zymosan-activated plasma $(26,27)$ or phorbol myristate acetate (28).

Since the GBS toxin induced changes in lung lymph flow and protein clearance were not significantly altered by depletion, it is likely that there are other mediators than those derived from granulocytes affecting the endothelium. The GBS toxin itself might have a direct effect on the endothelium. The possible influence of lymphocytes, macrophages, and other inflammatory cells on the GBS toxin response is not known. Lymphocytes might be involved in the response to GBS toxin, since the fall in blood concentrations of lymphocytes paralleled that of the granulocytes. Lung lymph concentration of lymphocytes fell consistently after GBS toxin administration, which was not explained by increased lymph flow.

It is possible that the observed effect on the GBS toxin response during granulocyte depletion is due to factors other than depletion of granulocytes. An increase in age in the lambs is not a likely explanation for the results, since the response to GBS toxin during the control studies did not vary with age. A direct effect of hydroxyurea itself is possible but we do not consider that to be likely. Studies of repeated administrations of endotoxin to sheep has shown that the endotoxin response was not affected by hydroxyurea treatment until granulocyte depletion was achieved (7, 9). However, Winn et al. (29) have recently reported that the increase in lung water observed after high doses of endotoxin was markedly attenuated in granulocyte-depleted goats after pretreatment with hydroxyurea but not after nitrogen mustard, suggesting that hydroxyurea prevents pulmonary edema following endotoxin by a mechanism other than granulocyte depletion. In five of the lambs, we were able to do a partial second control study after spontaneous granulocyte repletion. In this study, the changes in pulmonary arterial pressure and leucocyte counts were similar to what was seen in the first control study, before granulocyte depletion with hydroxyurea was started. This would indicate that tolerance to the toxin is not a likely explanation for the attenuated response in the granulocyte depleted state.
In summary, we found changes in lung mechanics, $\dot{V}_{\text {min }}$, arterial oxygen tension, pulmonary arterial pressure, lung lymph flow, and protein clearance after a type III group B streptococcal toxin infusion in young lambs. Granulocyte depletion with hydroxyurea markedly attenuated alterations in lung mechanics, pulmonary hypertension, hypoxemia, and increased Vmin, but it did not significantly change the increase in lymph protein clearance, an index of vascular permeability to protein or $\mathrm{TXB}_{2}$ lung lymph levels. The results indicate that granulocytes are involved as mediators of the changes in lung mechanics seen after GBS toxin infusion in young lambs. Granulocytes contribute to the pulmonary hypertension and decrease in arterial oxygenation, but other mediators appear to be responsible for the injury of the vascular endothelium.

Acknowledgments. The authors thank Drs. Mildred T. Stahlman, Kenneth L. Brigham, and James R. Snapper for their support and advice, Thomas G. Arnold for providing the plethysmograph electronics, Patricia Minton, RN, Barbara Hodges, Nancy Wickersham, Gayle King, Stanley Poole, and Rao Gaddipati for their skilled technical assistance and Diane Peevler for typing the manuscript.

The results were presented in part at the annual meeting of the Society for Pediatric Research, 1985.

\section{REFERENCES}

1. Horn KA, Meyer WT, Wyrick BC, Zimmerman RA 1974 Group B streptococcal neonatal infection. JAMA 230:1165-1167

2. Hellerqvist CG, Rojas J, Green RS, Sell S, Sundell H, Stahlman MT 1981 Studies of Group B $\beta$-hemolytic streptococcus. I. Isolation and partial characterization of an extracellular toxin. Pediatr Res 15:892-898

3. Rojas J. Green RS. Hellerqvist CG, Olegard R, Brigham KL, Stahlman MT 1981 Studies on Group B $\beta$-hemolytic streptococcus. II. Effect on pulmonary hemodynamics and vascular permeability in unanesthetized sheep. Pediat Res 15:899-904

4. Rojas J. Larsson LE. Hellerqvist CG, Brigham KL, Gray ME, Stahlman MT 1983 Pulmonary hemodynamic and ultrastructural changes associated with Group B streptococcal toxemia in adult sheep and newborn lambs. Pediatr Res 17:1002-1008

5. Rojas J. Larsson LE. Ogletree ML, Brigham KL, Stahlman MT 1983 Effects of cyclooxygenase inhibition on the response to Group B Streptococcal toxin in sheep. Pediatr Res 17:107-110

6. Rojas J. Palme C. Ogletree ML, Hellerqvist CG, Brigham KL, Stahlman, MT 1984 Effects of methylprednisolone on the response to group B streptococcal toxin in sheep. Pediatr Res 18:1141-1144

7. Hinson JM. Hutchinson AA, Ogletree ML, Brigham KL, Snapper JR 1983 Effect of granulocyte depletion on altered lung mechanics after endotoxemia in sheep. J Appl Physiol 55:92-99

8. Snapper JR, Hutchinson AA, Ogletree ML, Brigham KL 1983 Effects of cyclooxygenase inhibitors on the alterations in lung mechanics caused by endotoxemia in unanesthetized sheep. J Clin Invest 72:63-76

9. Heflin AC, Brigham KL 1981 Prevention by granulocyte depletion of increased vascular permeability of sheep lung following endotoxemia. J Clin Invest 68:1253-1260

10. Runkle B, Goldberg RN, Streitfeld MM, Clark MR, Buron E, Setzer ES, and Bancalari E 1984 Cardiovascular changes in Group B streptococcal sepsis in the piglet: Response to indomethacin and relationship to prostacyclin and thromboxane $A_{2}$. Pediatr Res 18:874-878

11. Spagnuolo PJ, Ellner JJ, Hassid A, Dunn MJ 1980 Thromboxane $A_{2}$ mediates augmented polymorphonuclear leukocyte adhesiveness. $J$ Clin Invest 66:406-414

12. Von Neergaard K, Wirz K 1927 Die Messing der Stromungsuiderstande in den Atemwegen des Menschen, Insbesondere bei Asthma und Emphysem. Z Klin Med 105:51-82

13. Dubois AB, Botelho SY, Bedell GN, Marshall R, Comroe JM, Jr 1956 A rapid plethysmographic method measuring thoracic gas volume: a comparison with a nitrogen washout method for measuring functional residual capacity in normal subjects. J Clin Invest 35:322-326

14. Ogletrec ML, Brigham KL 1982 Effects of cyclooxygenase inhibitors on pulmonary vascular responses to endotoxin in unanesthetized sheep. Prostaglandins Leukotrienes Med 8:489-502

15. Huttemeier PC, Watkins WD, Peterson MB, Zapol WM 1982 Acute pulmonary hypertension and lung thromboxane release after endotoxin infusion in normal and leukopenic sheep. Circ Res 50:688-694

16. Hyman AL, Spannhake EW, Kadowitz PJ 1978 Prostaglandins and the lung. Am Rev Respir Dis 117:111-136

17. Goldstein I, Malmsten C, Samuelsson B, Weissmann G 1977 Prostaglandins, thromboxanes and polymorphonuclear leukocytes: Mediation and modulation of inflammation. Inflammation 2:306-317 
18. Sacks T. Moldow CF. Craddock PR, Bowers TK, Jacob HS 1978 Oxygen radicals mediate endothelial cell damage by complement-stimulated granulocytes. An in vitro model of immune vascular damage. J Clin Invest 61:1161-1167

19. Hohn DC. Meyers AJ, Gherini ST, Beckmann A, Markison RE, Churg AM 1980 Production of acute pulmonary injury by leukocytes and activated complement. Surgery $88: 48-58$

20. Janoff A. White R. Carp H, Harel S, Dearing R, Lee D 1979 Lung injury induced by leukocytic proteases. Am J Pathol 97:111-135

21. Pratt PC. Vollmer RT. Shelburne JD, Crapo JD 1979 Pulmonary morphology in a multihospital collaborative extracorporeal membrane oxygenation projcct: I. Light microscopy. Am J Pathol 95:191-214

22. Flick MR, Perel A, Staub NC 1981 Leukocytes are required for increased lung microvascular permeability after microembolization in sheep. Circ Res 48:344-35!

23. Newman JH, Loyd JE. English DK, Ogletree ML, Fulkerson WJ, Brigham KL 1983 Effects of breathing $100 \%$ oxygen on lung vascular function in awake sheep. J Appl Physiol 54:1379-1386
24. Craddock PR, Fehr J, Dalmasso AP, Brigham KL, and Jacob HS 1977 Hemodialysis leukopenia: pulmonary vascular leukostasis resulting from complement activation by dialyzer cellophane membranes. J Clin Invest 59:879-888

25. Chenoweth DE, Cooper SW, Hugli TE, Stewart RW, Blackstone EH, Kirklin JW 1981 Complement activation during cardiopulmonary bypass: evidence for generation of $C_{3 a}$ and $C_{5 a}$ anaphylatoxins. $N$ Engl J Med 304:497-503

26. Shaw JO. Henson PM. Henson J, Webster RO 1980 Lung inflammation induced by complement-derived chemotactic fragments in the alveolus. Lab Invest 42:547-558

27. Meyrick BO, Brigham K 1984 The effect of a single infusion of zymosanactivated plasma on the pulmonary microcirculation of sheep: structurefunction relationships. Am J Pathol 114:32-45

28. Dyer EL, Snapper JR 1986 Role of circulating granulocytes in sheep lung injury produced by phorbol myristate acetate. J Appl Physiol 60:576-589

29. Winn R, Maunder R, Harlan J 1986 Neutrophil (PMN) depletion does not prevent pulmonary edema following infusion of highdose endotoxin. Fed Proc 45:400(abstr) 